\title{
EI sistema de arrendamientos y la monopolización de los ingresos fiscales en el Estado Soberano de Bolívar, 1860-1878
}

\author{
Roicer Alberto Flórez Bolívar $\left.{ }^{*}\right)$
}

Recibido: julio de 2011

Aprobado: octubre de 2011

\section{Resumen:}

Este artículo estudia los principales impuestos del Estado Soberano de Bolívar (Colombia) entre 1860 a 1878, los obstáculos que enfrentó la administración pública para la recaudación de los mismos, la debilidad de los fiscos distitales y del Estado regional y las resistencias opuestas por los ciudadanos a pagar los impuestos. La idea central es la de que la incapacidad de establecer un monopolio fiscal obligó al Estado a arrendar los principales impuestos de los que dependía su funcionamiento, cediendo la facultad de colectar los tributos a particulares, lo que en última significó la privatización del sistema de recaudo. Por esta vía el arrendamiento se constituyó en una fuente de acumulación de capital y en escenario de disputas políticas entra facciones interesadas en monopolizar el cobro de los recaudos.

\section{Palabras claves:}

Estado de Bolívar, sistema fiscal, liberalismo económico, monopolio fiscal.

\begin{abstract}
:
This article examines the main taxes of Sovereign State of Bolivar (Colombia) from 1860 to 1878, the obstacles faced by the government to raise them, the weakness of the Treasury and State distitales regional and resistance from citizen to pay taxes. The central idea is that the inability to establish a monopoly forced the state to lease the major taxes which depended its operation, yielding the power to collect taxes on individuals, which eventually meant the privatization of the collection system . This route was established in the lease a source of capital accumulation and the scene of factional political disputes enters interested in monopolizing the collection of collections.
\end{abstract}

Key words:

Bolivar state, tax system, economic liberalism, fiscal monopoly.

\footnotetext{
${ }^{(*)}$ Historiador de la Universidad de Cartagena y magister en Historia convenio Universidad Pedagógica y Tecnológica de Colombia-Universidad de Cartagena (tesis meritoria). Docente del Programa de Historia de la Universidad de Cartagena. Miembro del grupo de investigaciones Frontera, sociedad y cultura del Programa de Historia de la Universidad de Cartagena, categoría B, clasificación Colciencias. Ha publicado artículos en las revistas Historia Crítica (Universidad de los Andes), Cuadernos de Literatura del Caribe e Hispanoamérica (Universidad del Atlántico-Universidad de Cartagena), Historia Caribe (Universidad del Atlántico), Unicarta (Universidad de Cartagena), Historia y Sociedad (Universidad Nacional sede Medellín), Trenzando, Noventaynueve y otras revistas de circulación regional. aflorezb@yahoo.com
} 


\section{Presentación}

$\mathrm{E}$ n este trabajo analizo el sistema tributario del Estado Soberano de Bolívar ${ }^{1}$ entre 1860 a 1878. El objetivo que persigo es develar cuales eran los principales impuestos del Estado y que obstáculos tuvo que enfrentar la administración pública para la recaudación de los mismos. Dentro de las ideas que sustento se encuentran que durante el periodo de estudio el Estado Soberano de Bolívar vivió una inestabilidad económica como consecuencia de que este ni los distritos que lo conformaban producían los suficientes recursos para cubrir los gastos que demandaba su administración por la pobreza de sus habitantes y por la resistencia de los ciudadanos a pagar los impuestos. El contrabando, la evasión, el fraude eran algunas de las estrategias implementadas para evadir la recolección de los mismos. La incapacidad de establecer un monopolio fiscal obligó a que el Estado tuviera que someter al sistema de arrendamiento los principales impuestos de los que dependía su administración. Es decir, se cedió la facultad de recaudar los impuestos a ciudadanos particulares, lo que en última significó la privatización del sistema de recaudo.

\section{La tributación directa: modelo económico de los liberales decimonónicos}

En la Nueva Granada el triunfo de la ideología liberal durante la centuria decimonónica, supuso como una de sus variables fundamentales la consolidación del ciudadano. Para alcanzar este objetivo se adoptaron una serie de medidas entre las que sobresalió la disminución de la intervención estatal en la regulación de la economía, amparados en la creencia de que se debía dejar en las leyes del mercado la regulación de las economías nacionales. Pero otro de los puntos que se debatió fue ¿de qué manera los nuevos ciudadanos debían colaborar para el mantenimiento y sostenimiento de los nuevos entes territoriales? En la década de los sesentas cada uno de los Estados Soberanos de los Estados Unidos de Colombia, amparados en la autonomía política y económica de que disfrutaban, organizó su sistema de rentas y las actividades que se debían gravar. Lo que se

\footnotetext{
${ }^{1}$ Por Estado Soberano de Bolívar o Bolívar Grande se entiende la parte de la región Caribe colombiana comprendida entre el margen occidental del río Magdalena y el golfo de Urabá, abarcando los actuales territorios de los departamentos del Atlántico, Bolívar, Sucre y Córdoba. Durante la colonia y en la primera mitad del siglo XIX se le llamó Provincia de Cartagena y en el tercer cuarto de esa centuria Estado Soberano de Bolívar. A partir de 1886 se le conoció como Departamento de Bolívar, o Bolívar Grande. Su extensión estaba por encima de los 65.000 kilómetros cuadrados, siendo más grande que el $50 \%$ del territorio de los países de Europa, que todos los países del Caribe insular (excepto Cuba) y que El Salvador y Costa Rica. Ver: Sergio Paolo Solano, Roicer Flórez y William Malkún, "Ordenamiento territorial y conflictos jurisdiccionales en el Bolívar Grande, 1880-1886", en Historia Caribe $\mathrm{N}^{\circ}$ 13, Barranquilla, Universidad del Atlántico, 2008, pp. 65-119.
} 
buscaba era establecer un sistema de impuestos con base en los principios liberales de equidad, igualdad y proporcionalidad ${ }^{2}$.

La polémica estaba en si se establecía un sistema tributario de características directas que gravara los ingresos, o uno indirecto con base en los impuestos al consumo. El problema que veían algunos liberales con ésta última alternativa era que resultaba inequitativa porque no se tenía en cuenta la renta de cada uno de los ciudadanos y debían pagar el mismo gravamen. Para muchos liberales, la equidad sobre la que se basaba el sistema tributario directo lo convertía en el más aceptable y tolerable, porque en él se contemplaba la fórmula de que todo ciudadano, sin distinción alguna, tenía la obligación de contribuir a los gastos inherentes del Estado y dichas contribuciones se repartían entre todos en proporción a sus facultades y no distorsionaba el funcionamiento del mercado ${ }^{3}$.

Para el caso del Estado Soberano de Bolívar, desde su creación, se intentó montar un sistema de tributación directa. Para ello, a mediados de la década de los sesentas se gravaron las tres actividades económicas más importantes como lo eran el comercio, la ganadería y la agricultura, estableciendo los impuestos conocidos como comercial o general, el de cría, levante y degüello de ganado y el impuesto agrario ${ }^{4}$. Sin embargo, el haber gravado estas industrias suscitó un rechazo unánime y un enfrentamiento entre los comerciantes, ganaderos, hacendados y terratenientes con el Estado. De todas las provincias tanto los ciudadanos particulares como las autoridades provinciales y distritales se quejaban por lo que consideraban un abuso. Por ejemplo, en 1865 en Mompox, los principales comerciantes, quienes integraban el concejo municipal, tomaron la decisión de no acatar la aplicación de la ley. Luego de publicado un edicto en el que se señalaba que la provincia debía contribuir con la suma de \$7.000,oo; el 21 de agosto el gobernador, Juan Rives, convocó a una reunión en la plaza pública a los comerciantes. El objetivo de la citación era explicar la ley que gravaba esta actividad y la discusión debía centrarse en los siguientes puntos: ¿quiénes eran comerciantes?, ¿quiénes se ocupaban de operaciones mercantiles en esa provincia? y ¿con que cantidad debían contribuir cada cual?

Hechas estas aclaraciones, se procedió a establecer la cantidad que a cada uno le correspondía cancelar. Sin embargo tres días después de haberse aprobada la ley, el concejo municipal resolvió abstenerse de cumplirla y solicitar la anulación de los actos de la corte suprema federal. Al mismo tiempo, el alcalde principal, Teniente Coronel Bruno

\footnotetext{
${ }^{2}$ Jaime Sempere y Horacio Sobrazo, "El federalismo fiscal en México", en Memorias del XIII ${ }^{\circ}$ Congreso Colombiano de Historia, Bucaramanga, Universidad Industrial de Santander-Universidad Nacional sede Medellín, 2006.

${ }^{3}$ Esperanza Donjuán Espinosa, "Las finanzas públicas en Sonora en la primera mitad del siglo XIX. La cuestión fiscal", en www.cholonautas.edu.pe.bibliotecavirtualdecienciassociales. (Consulta: abril 23 de 2007)

${ }^{4}$ Biblioteca Bartolomé Calvo (Colombia) [BBC], Colección de prensa microfilmada, Gaceta de Bolívar, Cartagena, junio 24 de 1865.
} 
Campo, como su suplente, Gervasio Castellano, renunciaron alegando excusas legales. Para salir de la crisis administrativa en que se encontraba la Ciudad, el gobernador nombró en reemplazo de los anteriores funcionarios a José del Castillo y Sabas Martínez Troncoso. Ambos se excusaron fundándose en que no querían darle cumplimiento al decreto expresado. Aunque Rives insistió en el llamamiento, Martínez Troncoso se volvió a negar argumentando que tanto la constitución de la Nación como la del Estado habían abolido los empleos onerosos. Un mes después, Juan Rives renunció al cargo alegando que "su conducta digna e intachable no era del agrado de los señores notables de ese lugar, los que a falta de hechos que censurar, se valían de intrigas y falsedades para desprestigiar su administración". Y agregaba

\begin{abstract}
La independencia y honradez en el desempeño de cualquier destino público, no son los dotes que se requieren para obtener la aprobación de las gentes que se titulan sensatas en esta desgraciada ciudad. El empleado que quiera atraerse las simpatías de ellas, tiene que seguir sus inspiraciones e inclinar humilde su frente ante el querer de estos GAMONALES, que quieren dirigir la política detrás de bastidores, creyéndose los árbitros de los destinos de esta población... y por esa razón, Sr. Secretario, renuncio el destino de Gobernador de esta Provincia 5 .
\end{abstract}

Finalmente, los impuestos de contribución comercial, cría y levante de ganado fueron suprimidos. No era necesario llegar al extremo como en Mompox. Para ello, el sector comercial, ganadero y hacendatario, utilizó el poder político con que contaba en el Estado. La Asamblea Legislativa, órgano que controlaban políticamente y que era la encargada del establecimiento del sistema rentístico, decretó en el año de 1869 la eliminación de los anteriores gravámenes. Solo quedó el impuesto al consumo de carne de ganado vacuno y de cerda porque este no afectaba en nada sus intereses económicos, sino que recaía sobre los consumidores. De esta manera, el sistema tributario que se estableció en el Estado Soberano de Bolívar, descansó, en su mayor parte, sobre los impuestos indirectos.

Sin embargo, en reemplazo de los anteriores gravámenes, ese mismo año se estableció el impuesto sobre la renta, que era una contribución de carácter directo, el que junto al degüello y a la destilación y rectificación de aguardientes se convirtieron en los impuestos más importantes para el mantenimiento de la administración pública. Así, durante los años transcurridos entre 1869 a 1878 el sistema tributario del Estado se caracterizó por ser de naturaleza mixta, en el que se combinaban los impuestos directos (impuesto sobre la renta) con los indirectos, (impuesto al consumo de carnes de ganado vacuno y de cerda, de harina, azúcar, tabaco, café y cacao, impuesto a la destilación, rectificación e introducción de

\footnotetext{
${ }^{5}$ BBC, Gaceta Oficial del Estado Soberano de Bolívar, Cartagena, septiembre 6 de 1865. Mayúsculas en el original.
} 
aguardientes y otros de menor cuantía como el impuesto sobre las herencias, papel sellado, derecho de minas, correos, etc.) ${ }^{6}$.

\section{Análisis del rendimiento de los impuestos en las provincias}

Los impuestos al consumo de carne de ganado vacuno y de cerda, sobre la renta y de destilación y rectificación de aguardientes representaban para el Estado entre el 80\% y el $85 \%$ de su presupuesto de rentas. Durante los años de 1869 a 1878, las sumas que les fueron adjudicadas a estos tres impuestos en el presupuesto de rentas fueron las que aparecen registradas en el cuadro 1. Ahora bien, si se toma el presupuesto de rentas del Estado de 1869 que ascendía a la suma de \$184.800,oo, se suman el valor de los impuestos al degüello, de la renta y de destilación y rectificación de aguardientes que era de $\$ 154.000,00$, y si se aplica una regla de tres simples para conocer el porcentaje que representaban, el resultado que se obtiene es el de $83,3 \%$ del total.

Cuadro 1

Sumas adjudicadas a los principales impuestos del Estado de Bolívar, 1869-1878

\begin{tabular}{|c|c|c|c|}
\hline Año & $\begin{array}{c}\text { Consumo de carne y } \\
\text { vacuno y cerda }\end{array}$ & $\begin{array}{c}\text { Impuesto sobre } \\
\text { la renta }\end{array}$ & $\begin{array}{c}\text { Destilación, rectificación e } \\
\text { Introducción de aguardiente }\end{array}$ \\
\hline 1869 & 75.000 & 60.000 & 19.000 \\
\hline 1873 & 85.000 & 27.000 & 17.000 \\
\hline 1874 & 85.000 & 50.000 & 25.000 \\
\hline 1875 & 90.000 & 64.000 & 13.100 \\
\hline 1876 & 90.000 & 80.000 & 12.000 \\
\hline 1877 & 90.000 & 100.000 & 12.000 \\
\hline 1878 & 90.000 & Se suprimió & 12.000 \\
\hline
\end{tabular}

El impuesto al degüello representaba el 40,5\% del total, el impuesto sobre la renta 32,4\% y el de destilación y rectificación de aguardientes el 10,2\%. El 16,9\% restante se dividía entre impuestos menores como el consumo de harina, azúcar, café y tabaco, equivalente al $5.4 \%$, que representado en peso era una suma de 10.000 ; papel sellado el $4.3 \%$ ( $\$ 8.000,00)$; registro de instrumentos públicos y privados el $1.3 \%$ equivalente al precio de $\$ 3000$,oo; igual porcentaje que el anterior para las rentas incorporadas. El 4.6\% se dividía entre las mortuorias $(\$ 500,00)$; Dique y sus pasos $(\$ 500,00)$; correos $(\$ 1.300,00)$; venta de ediciones oficiales $(\$ 150,00)$; aprovechamientos $(\$ 100,00)$; bienes del Estado $(\$ 50,00)$.

\footnotetext{
${ }^{6}$ Algunas notas sobre las finanzas públicas del Estado Soberano de Bolívar, aparecen en el artículo de Alberto Hong Hiu, "las finanzas públicas en el Estado Soberano de Bolívar, 1857-1886", en Historia y Pensamiento No 3, Barranquilla, Universidad del Atlántico, 1999, pp. 28-36.
} 
No obstante, los impuestos al degüello, sobre la renta y el de destilación, rectificación e introducción de aguardientes tenían un rendimiento diferente en cada una de las provincias del Estado. En las de Barranquilla y Cartagena resultaba más productivo y fácil de cobrar el impuesto sobre la renta. En 1873, el tesorero general del Estado manifestaba que cada día se hacía más difícil el cobro de este impuesto, pero que sobre ese particular debía hacer una honrosa mención de la provincia de Barranquilla, "cuyos habitantes contribuyentes de dicho impuesto, lo satisfacen casi en absoluto, religiosamente". El contraste eran las de Sincelejo y Magangué. En el caso de la primera, este gravamen nunca fue aceptado por sus ciudadanos, con esto no quiero decir que en las demás sí, pero allí fue mucho más notable la animadversión. En 1874, su gobernador comentaba que la ley sobre el impuesto sobre la renta "ha sido generalmente mal recibida, y si no me equivoco, ella no es solamente mal rechazada sino que hasta su título se ha hecho odioso, y esto es tan cierto, que la mayor parte de los calificados, elude de cualquier manera el pago del impuesto que por ella se establece"7. En el caso de Magangué, las razones por las que el rendimiento de este impuesto y el del consumo de carnes de ganado vacuno y de cerda eran ínfimos, en comparación con Barranquilla y Cartagena, se debía a que era la provincia más pobre y la menos poblada. Además, en Magangué era muy reducido el número de ciudadanos que tenían la cantidad de $\$ 300$ anuales establecido por el Estado para cancelar el impuesto sobre la renta.

\section{Cuadro 2}

\section{Principales impuestos del Estado Soberano de Bolívar ${ }^{8}$}

\begin{tabular}{|c|c|c|c|c|c|c|c|c|c|c|}
\hline $\begin{array}{l}\text { Provincias } \\
\text { Impuestos }\end{array}$ & 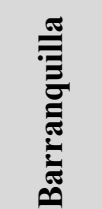 & 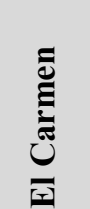 & 营 & సี & 兰 & . & 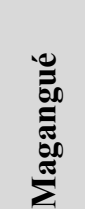 & 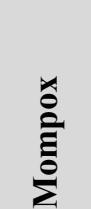 & 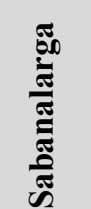 & 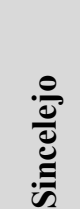 \\
\hline $\begin{array}{l}\text { Consumo de } \\
\text { carnes de } \\
\text { ganado } \\
\text { vacuno y de } \\
\text { cerda } \\
\end{array}$ & 12.610, & 9.080 & 15.912, & 9.358 & 5.260, & 8.220 , & 2.992, & 6.820 & 6.680 & 7.520, \\
\hline $\begin{array}{l}\text { Impuesto } \\
\text { sobre la } \\
\text { renta }\end{array}$ & 15.000, & 4.750 , & 12.000, & 4.500 & 6.000, & 6.000 & 3.000 , & 4.750 & 3.500 & 4.500, \\
\hline $\begin{array}{l}\text { Destilación, } \\
\text { rectificación, } \\
\text { introducción y } \\
\text { consumo de } \\
\text { aguardiente }\end{array}$ & 3.734 & 1.530 & 3.380 & 1.486, & 720,00 & 2.680 & 3.085 , & 4.000 & 3.215 & 3.338 , \\
\hline
\end{tabular}

${ }^{7}$ BBC, Gaceta de Bolivvar, Cartagena, agosto 25 de 1873; Diario de Bolívar, agosto 14 de 1874 y agosto 9 de 1875 .

${ }^{8}$ Fuentes: BBC, Gaceta de Bolívar, Cartagena, octubre 31 y noviembre 28, y noviembre 30 de 1873. 
Igual sucedía con el de destilación y rectificación. Las provincias en las que este gravamen producía mayores rendimientos eran Mompox, Barranquilla, Cartagena, Sincelejo, Sabanalarga y Magangué. De estas, la única en la que no se consolidó el cultivo de la caña de azúcar fue la de Barranquilla, pero contaba con el mercado más amplio de todo el Estado. En las que menos producía el gravamen en mención era en las de Chinú, El Carmen y Corozal. La explicación obedecía a que en estas el cultivo de caña de azúcar y la fabricación de aguardientes no eran predominantes, siendo abastecidas de este último producto por las provincias de Magangué y Sincelejo?.

Lo anterior no significa que lo recaudado en las provincias por concepto de estos impuestos fuera suficiente para cubrir los gastos que demandaban su administración. En cada una de estas entidades existía una profunda crisis económica y administrativa relacionada con la falta de recursos. Frente al panorama desalentador de la mayoría de las provincias, las soluciones inmediatas que veían algunos gobernadores era suprimir algunos de estos entes territoriales, como lo planteaba el gobernador de Corozal en 1874. Para este funcionario, aunque la administración pública del Estado perdería, la solución era:

...se suprimieran las entidades provinciales en que está dividido el Estado para su régimen administrativo, y se establecieran jefaturas municipales en cada distrito, que se comunicaran directamente con las oficinas de Ud., y que atendieran a la vez lo político y municipal.

...la suma de $\$ 125.000$ aproximadamente economizaría el Estado con esta medida que someto a la consideración del Poder Ejecutivo;... y no estaría subdividido el Estado en secciones raquíticas como la de Magangué, Sincelejo y esta de mi mando, que sin embargo consumen cantidades considerables en el sostenimiento de sus empleados ${ }^{10}$.

En síntesis, aunque la crisis económica que padecía el Estado era de carácter general, en algunas provincias se sentía con mayor fuerza. En las de Barranquilla, Cartagena, Lorica y Sabanalarga era menos dramática, en comparación con lo que sucedía en Magangué y Corozal. Como corolario, los sueldos que recibían los empleados provinciales eran diferentes. Por ejemplo, en 1878 los gobernadores provinciales ganaban los siguientes sueldos: el de Barranquilla \$100, Mompox y Lorica $\$ 80$, oo, Sabanalarga $\$ 60$, oo y Magangué \$46,oo ${ }^{11}$.

\footnotetext{
${ }^{9}$ Al respecto ver: Roicer Flórez Bolívar, El uso privado de la autoridad pública en el Estado Soberano de Bolivar, 1863-1878, Trabajo de grado para optar al título de Magister en Historia, convenio Universidad Pedagógica y Tecnológica de Colombia-Universidad de Cartagena, 2007.

${ }^{10} \mathrm{BBC}$, Gaceta de Bolivar, Cartagena, julio 30 de 1874.

${ }^{11}$ Archivo Histórico de Cartagena (Colombia), (AHC), Manuscritos. Fondo Gobernación, sección distritos y municipios, abril 8 y 30 de $1878, \mathrm{~N}^{\circ} 142$.
} 
De igual forma, lo que se vivía en las provincias se reproducía en los distritos. Algunos como las capitales provinciales contaban con mejor suerte que la mayoría de las entidades análogas, que prácticamente no tenían una renta estable de la que derivar el mantenimiento de la administración municipal. En los distritos-capitales la situación era menos tensa porque sus rentas eran diferentes al resto de los distritos y los rendimientos que se obtenían por los impuestos sobre la renta, al consumo de carne de ganado vacuno y de cerda y los de destilación, rectificación e introducción de aguardientes no eran iguales. Se daba el caso que en algunas provincias, un solo distrito abarcaba cerca del $80 \%$ o $85 \%$ del total de la suma que se establecía para los impuestos. En esto influía el número de sus habitantes y la riqueza de los mismos.

Las mayores y mejores ventajas siempre las tuvieron las capitales provinciales como Barranquilla, Cartagena, Sincelejo, Corozal, Chinú, Lorica, Magangué, El Carmen, Sabanalarga y Mompos por ser los más poblados en cada una de sus respectivas provincias. Si se comparan lo que produjo en el año de 1873 los impuestos sobre la renta y el de consumo de carnes de ganado vacuno y de cerda en cada uno de los distritos de la provincia de Barranquilla, que era la más rica del Estado, y en los de Magangué, la más pobre, se pueden sacar algunas conclusiones:

Cuadro 3

Impuestos sobre la renta y el de consumo de carnes provincias de Barranquilla y Magangué ${ }^{12}$

\begin{tabular}{|c|c|c|}
\hline \multicolumn{3}{|c|}{ Provincia de Barranquilla } \\
\hline Distritos & Impuesto sobre la renta & $\begin{array}{l}\text { Consumo de carnes de } \\
\text { ganado vacuno y de cerda }\end{array}$ \\
\hline Barranquilla & $\$ 13.500$ & $\$ 8.000$ \\
\hline Soledad & 460 & 1.610 \\
\hline Sabanagrande & 200 & 600 \\
\hline Santo Tomás & 300 & 1.550 \\
\hline Galapa & --- & 400 \\
\hline Tubará & 300 & 550 \\
\hline Malambo & 120 & --- \\
\hline Palmar de Varela & 120 & --- \\
\hline Total & $\$ 15.000$ & $\$ 12.610$ \\
\hline \multicolumn{3}{|c|}{ Provincia de Magangué } \\
\hline Magangué & $\$ 1.200$ & $\$ 1.672$ \\
\hline Majagual & 700 & 385 \\
\hline Sucre & 300 & 660 \\
\hline Yatí & 200 & 100 \\
\hline Madrid & 600 & 75 \\
\hline Palmarito & --- & 100 \\
\hline Total & $\$ 3.000$ & $\$ 3.992$ \\
\hline
\end{tabular}

${ }^{12}$ Fuente: BBC, Gaceta de Bolivar, Cartagena, noviembre 28, y 30 de 1873. 
La primera es que las rentas que producían estos dos distritos-capitales por concepto de los impuestos arriba señalados, eran totalmente diferentes. Mientras que Barranquilla producía por impuesto sobre la renta el $90 \%$ del total de la provincia, Magangué solo llegaba del $40 \%$. En el caso del impuesto al consumo de carnes de ganado vacuno y de cerda se nota un equilibrio en el porcentaje que representaban ambas capitales. Barranquilla abarcaba alrededor del 63.4\% del total producido en la provincia y Magangué cobijaba el 55,8\%.

Segundo, es mucho más notorio el desbalance que existía en la provincia de Barranquilla entre su capital y el resto de distritos que la integraban, que en la de Magangué. La capital de aquella, por concepto del impuesto sobre la renta, abarcaba el $90 \%$ del total de la provincia. El restante 10\% se dividía entre los distritos de Soledad, Sabanagrande, Tubará, Malambo, Palmar de Varela. Ahora bien, dentro de estos también había diferencias en lo que producían por el cobro de los impuestos que se están analizando. Soledad aportaba 3\% del impuesto sobre la renta, Tubará y Santo Tomás un 2\%, Sabanagrande con el $1.42 \%$ y Malambo y Palmar de Varela con el $0.88 \%$.

Así, lo que se nota en la provincia de Barranquilla es un abismal desbalance en las rentas con las que contaban sus distritos y la concentración de los escasos recursos económicos en la capital provincial. En la de Magangué, aunque había un notable diferencia entre lo que producía su capital y el resto de distritos, esta no era tan inmensa. Por ejemplo, el distrito de Magangué producía el $40 \%$ de lo que se recaudaba en la provincia por el impuesto sobre la renta. Después le seguía Majagual con el 23,3\%, Madrid con el 20\%, Sucre con el 10\% y Yatí con el $6.6 \%$. En esta provincia no era tan notable la concentración de los escasos recursos en su capital.

\section{"El mayor número de los distritos carece de rentas..."}

Si obedeciendo a la ley de descentralización de rentas y gastos, a cada distrito le correspondía decretar impuestos sobre los productos o efectos que no estaban gravados por la Nación o por el Estado; la administración, recaudación, contabilidad e inversión de sus propias rentas; la pregunta que resulta es ¿de qué rentas disponían los distritos, siendo que actividades como la ganadería y la fabricación de aguardientes ya había sido gravadas por el Estado?

Al ser mutilado por la nación de su principal impuesto como era la aduana, el Estado Soberano de Bolívar se vio en la necesidad de gravar dos de las tres actividades económicas más importantes de sus habitantes, lo que tuvo un impacto negativo sobre las economías distritales. Así, por la pobreza de sus habitantes, eran muy pocas las alternativas que tenían las administraciones distritales para establecer gravámenes, lo que terminó enfrentándolas con el Estado por el control de los escasos recursos económicos de que se disponía. En 1867, el gobernador de la provincia de Sabanalarga anotaba lo siguiente: 
...el sistema rentístico de los distritos, no necesita ningún esfuerzo para comprender que está sujeto a un verdadero desgreño. Destituidos los distritos de la mayor parte del degüello de ganados que constituía su más pingüe renta, y con la prohibición de establecer impuestos sobre los objetos gravados por el Estado, ha quedado completamente mutilada la soberanía municipal y aquellos sin objetos sobre que imponer contribuciones ${ }^{13}$.

Para las autoridades distritales el sistema rentístico establecido por el Estado en vez de fomentar el federalismo y la descentralización política administrativa, lo que hizo fue generar una centralización fiscal de los impuestos, dejándolos en la completa ruina. De esta manera, la organización federal aparecía como poca innovadora debido a que no provocó una federalización del sistema fiscal, sino solamente un fortalecimiento de la autonomía del Estado ${ }^{14}$, afectando el funcionamiento de la administración pública en los distritos como consecuencia de que no contaban con los suficientes recursos económicos para cancelar el pago de sus empleados, la construcción de escuelas, cárceles, dotación de materiales de las oficinas públicas, etc. En 1869, Manuel Cabeza, gobernador de la provincia de El Carmen señalaba que "se nota un desagrado casi general en la provincia no por los actuales impuestos que forman la renta del Estado, sino por la miseria en que por ellas se encuentran los distritos, de tal modo, que no tienen con qué pagar los gastos de escritorio de sus oficinas..."15. Nueve años después, el gobernador de Sabanalarga señalaba la misma situación en los distritos de su provincia:

Los distritos de Candelaria, Campo de la Cruz, Juan de Acosta, Manatí, Palmar de Candelaria, Piojó, Repelón, Soplaviento y Usiacurí, llaman verdaderamente la atención por la escasez de sus productos rentísticos,...pues se ve que el de Campo de la Cruz, que es el que arroja mayor cifra, solo gasta en el servicio de su administración, la suma mensual de $\$ 32,04 \frac{1}{2}$; pero es todavía más notable en el distrito de Soplaviento, que opera el gran milagro de sostener su vida política con solo el gasto mensual de $\$ 2,611 / 2$ centavos. De esto resulta, que el mayor número de los distritos carece de rentas; y por consiguiente, su marcha administrativa no puede ser rígida... ${ }^{16}$

Frente a este panorama, la solución diseñada por el Estado fue cederle algunos de los impuestos que estaban bajo su mando como la venta al por menor de aguardientes y darle un porcentaje de lo que se recaudaba por algunos de ellos, en este caso un tercio del

\footnotetext{
${ }^{13}$ BBC, Gaceta de Bolivar, Cartagena, septiembre 10 de 1867.

${ }^{14}$ E. Donjuán, "Las finanzas públicas en Sonora en la primera mitad del siglo XIX. La cuestión fiscal”, p. 8 .

${ }^{15}$ BBC, Gaceta de Bolivar, Cartagena, septiembre 5 de 1869.

${ }^{16} \mathrm{BBC}$, Diario de Bolivar, Cartagena, agosto 6 de 1879
} 
impuesto al degüello conocido como las terceras municipales y consistía en que el Estado les daba a cada distrito un tercio de lo producían por el impuesto al consumo de carne de ganado vacuno y de cerda. Como el dinero que se cancelaba por cada res que se sacrificaba era de $\$ 3,20$ y de esto se descontaba un $8 \%$ por concepto de la recolección, es decir 25,6 centavos, a las arcas del Estado entraban $\$ 1,96$ y a la de los distritos 97 centavos.

No obstante, los recaudos que producían la venta al por menor de aguardientes y las terceras municipales no eran suficientes para cubrir los gastos que demandaban la administración pública de los distritos. En el caso del primer impuesto era difícil obtener grandes rendimientos porque quienes ejercían esta actividad eran, en su gran mayoría, los ciudadanos más pobres. En 1869, el gobernador de la provincia de Barranquilla refiriéndose al impuesto a la venta por menor de aguardientes manifestaba que "la venta por menor de aguardiente es el impuesto que más dificultades presenta para su cobro, por la razón de que los individuos que la pagan son en su mayoría enteramente infelices...". Ni siquiera en la provincia de Sincelejo, que era una de las que más producía por concepto de este impuesto, se obtenían buenos resultados. En 1872, su gobernador manifestaba que el rendimiento que se había obtenido por la venta al por menor de aguardiente en Tolú viejo en el semestre corrido desde Enero hasta Junio de ese año era el de 12 pesos; es decir, dos pesos por $\operatorname{mes}^{17}$.

En cuanto al impuesto al degüello, existían diversas razones que determinaban que los ingresos que recibían los distritos por concepto de las terceras municipales fueran también diferentes. La primera de ellas obedecía al número de habitantes de cada uno de los distritos. No era igual el rendimiento que se obtenía en Barranquilla, Sincelejo y Cartagena, con poblaciones de $11.595,11.336$ y 8.603 habitantes, respectivamente, al que se tenía en los distritos San Fernando, Arroyo Grande, María la Baja, etc., cuyas poblaciones no llegaban, según el censo de 1881, a los mil habitantes. Así, en las tres primeras poblaciones el consumo de carne de ganado vacuno iba a ser muy superior con relación a las tres últimas.

Lo mismo sucedía al interior de las provincias. En 1871 el gobernador de Mompos ponía de presente que los colectores de los distritos nada recaudaban por los impuestos y hasta el del consumo de carnes, que era casi la única contribución que percibían, era ridícula. Por ejemplo, en el distrito de Talaigua, que tenía 992 habitantes, se consumieron solo 3 cerdos en el mes de Enero; en Pinillos los 1.967 habitantes que tenía consumieron en los meses de Enero y Febrero 2 cerdos; Morales, población de 3.354 habitantes consumió una res y 3 cerdos en el mes de Febrero, los 1.884 habitantes del distrito de Simití solo alcanzaron a consumir 3 cerdos en el mes de Enero; loba con 1318 habitantes, consumió en el mes de Marzo 1 res y 6 cerdos; Barranco, que tenía 1.318 habitantes consumió en el mes de

\footnotetext{
17 Sobre los informes de los gobernadores de Barranquilla y Sincelejo ver: BBC, Gaceta de Bolívar,
} Cartagena, septiembre 12 de 1869 y Diario de Bolívar, Cartagena, julio 22 de 1872. 
Febrero $3 \operatorname{cerdos}^{18}$. El resultado que se obtuvo en las provincias de Corozal, El Carmen y Mompos en el mes de Marzo de 1873 sobre el consumo de carne de ganado vacuno y de cerda en cada uno de los distritos que las integraban pueden verse en el cuadro 4.

Cuadro 4

Impuestos recaudados por concepto de consumo de carnes ${ }^{19}$

\begin{tabular}{|l|c|c|l|l|c|c|c|c|}
\hline \multicolumn{2}{|c|}{ Provincia de Corozal } & \multicolumn{2}{c|}{ Provincia de El Carmen } & \multicolumn{2}{c|}{ Provincia de Mompox } \\
\hline Distritos & Reses & Cerdos & Distritos & Reses & Cerdos & \multicolumn{1}{c|}{ Distritos } & Reses & Cerdos \\
\hline Corozal & 96 & 33 & Carmen & 160 & 23 & Mompox & 144 & 56 \\
\hline Sincé & 84 & 26 & $\begin{array}{l}\text { San } \\
\text { Jacinto }\end{array}$ & 48 & 12 & San Fernando & 1 & 1 \\
\hline Ovejas & 38 & 5 & San Juan & 23 & 4 & Loba & 0 & 1 \\
\hline Galeras & 11 & 4 & Zambrano & 18 & 2 & Pinillos & 3 & 7 \\
\hline Morroa & 1 & 1 & Tetón & 6 & 4 & Simití & 2 & 4 \\
\hline & & & Guamo & 0 & 0 & Morales & 7 & 7 \\
\hline & & & Yucal & 0 & 0 & Talaigua & 0 & 0 \\
\hline & & & Barranca & 0 & 0 & $\begin{array}{l}\text { San Martín de } \\
\text { Loba }\end{array}$ & 0 & 0 \\
\hline
\end{tabular}

Otro factor que no era favorable para el cobro de las terceras municipales se debía a que muchos distritos estaban ubicados a orilla de los ríos, ciénagas, caños, etc. ${ }^{20}$, lugares en los que el consumo de carne no era el alimento principal de la dieta alimenticia, como si lo era el pescado. Los meses más duros para las entradas del impuesto sobre el consumo de carne de ganado vacuno y de cerda eran enero, febrero, marzo y abril, por la competencia que a la carne hacía en ese periodo el pescado. En 1878 el gobernador de la provincia de Chinú manifestó:

Desde que se suprimió el impuesto sobre la renta, se redujeron los de esta provincia al que grava al consumo de carnes de ganado vacuno y de cerda, a los que gravan el producto de destilación y rectificación de aguardientes; y a los demás proventos fiscales. El primero de dichos impuestos es poco progresivo, en razón a que solo tres distritos de la provincia no están situados a las márgenes de ríos y ciénagas, en donde la pesca suple el consumo de carne ${ }^{21}$.

En la provincia de Mompós el rendimiento del impuesto al degüello se alteraba por dos factores: el primero era que solo en su distrito capital era rentable este impuesto, porque "los pueblos de esta provincia, casi en su totalidad se alimentan de la pesca; así es que no

\footnotetext{
${ }^{18}$ BBC, Diario de Bolivar, Cartagena, agosto 16 de 1871.

${ }^{19}$ Fuente: AHC, fondo Manuscritos, Sección Provincias, Caja № 29, marzo 12 de 1873.

${ }^{20}$ Una quinta parte de la superficie de la Costa Caribe estaba conformada por ríos, caños, ciénagas y pantanos.

${ }^{21}$ BBC, Diario de Bolivar, Cartagena, agosto 27 de 1878.
} 
debe extrañarse lo escaso del producto del impuesto sobre el consumo de carnes" ${ }^{, 2}$. El segundo era el fuerte contrabando proveniente del Estado del Magdalena, como consecuencia de que la línea divisoria que los separaba era el río de este mismo nombre y por consiguiente era sumamente fácil cometer el fraude. Lo que se hacía era que se daba muerte a las reses en el Estado vecino y se introducían las carnes en altas horas de la noche, para luego ser expendidas de una manera sigilosa. Por grande que fuera la vigilancia que se ejerciera por los empleados de policía y de hacienda, en laderas tan extensas, era imposible evitar el fraude como lo ponía de presente en 1870 el gobernador de esa provincia, Juan del Villar:

\begin{abstract}
A la vista de esta Ciudad se encuentran unas pocas casas en territorio del Estado del Magdalena, donde individuos de esta Ciudad benefician sus ganados y luego pasan parte de la carne a esta plaza, pagando por su introducción un pequeño derecho. Habida consideración de que el resto de la carne del ganado que se benefician en ese punto del territorio del Estado del Magdalena no puede consumirse en él, por ser muy reducido de sus pobladores, se cae en cuenta que lo que pasa es un medio de hacerse contrabando, introduciendo sigilosamente el resto de la carne para ser consumida en esta Ciudad. De esto se tiene ya un hecho práctico, pues de un cuarto de res que se presentó al administrador de hacienda para que la pesara y dedujera el derecho de introducción, se dio margen para solicitar las carnes que faltaban, la que fue hallada en esta Ciudad y se sujetó al pago del derecho... ${ }^{23}$
\end{abstract}

Así, los ingresos que recibían las entidades distritales por concepto de las terceras municipales eran enteramente diferentes. En 1870 al distrito de Barranquilla le correspondió la suma $\$ 426,90$; El Carmen $\$ 158,02,1 / 2$, a Corozal $\$ 102,85$. En contraste, Momil, Achí, Madrid recibieron las ínfimas sumas de \$2, 83, \$2,73, \$1,45. Se daban casos extremos como el de Yatí, en la provincia de Magangué, en el que el impuesto al consumo de carne de ganado vacuno y de cerda fue arrendado a Pedro R. Porto por la suma de $\$ 37,50$; por tanto su administración distrital recibiría ese año por concepto de la tercera municipal 97 centavos y con esa suma tenía la obligación de pagar a todos sus funcionarios públicos, la creación de escuelas y de cárcel, dotar de los materiales que necesitaban las diferentes dependencias, mejoramiento de las vías, etc. ${ }^{24}$.

El problema de esto era que casi todos los distritos estaban atenidos al recurso precario de la tercera parte del impuesto al consumo de carnes. Cuando por cualquier circunstancia se les retiraban, quedaban sus empleados sin esperanza de que se les remunerara sus servicios y

\footnotetext{
${ }^{22}$ BBC, Diario de Bolivar, Cartagena, agosto 16 de 1876.

23 AHC, Manuscritos, Fondo Gobernación, Sección Hacienda, 1873-1933. Caja No 21, Mompós, marzo 2 de 1870 .

${ }^{24}$ BBC, Diario de Bolivar, Cartagena, septiembre 17 de 1870.
} 
por consiguiente la administración pública era irregular, produciendo trastornos en la marcha ordenada de los ramos del servicio provincial. Debido a esto, los distritos siempre se encontraban con déficit enormes para cancelar las deudas que los apremiaban. En 1877, el gobernador de la provincia de El Carmen señalaba que

El tesoro de los distritos está en un estado de postración lamentable. No hay rentas para atender medianamente al pago de los sueldos de los empleados distritoriales. La tercera municipal, el impuesto sobra la venta por menor de aguardientes..., no producen lo suficiente para el objeto indicado. Distritos hay en esta provincia, como Barranca, en que los empleados públicos fundan toda su esperanza en la tercera municipal, que hoy, que dichos derechos están allí rematados, asciende a $\$ 1.87,1 / 2^{25}$.

\section{EI laboratorio fiscal de los distritos: Concejos municipales versus Tribunal Superior de Justicia}

Si las terceras municipales y la venta por menor de aguardientes no producían los suficientes recursos para el mantenimiento de la administración pública de los distritos, ¿Qué alternativas planteaban los concejos municipales?, ¿sobre qué otros objetos o actividades establecían gravámenes? Efectivamente, casi todos los concejos municipales planteaban alternativas de posibles impuestos que se podían establecer para mejorar las rentas distritales. El problema estribaba en que casi no había objetos para gravar legalmente, porque o ya estaban gravados por la nación o lo estaban por el Estado, lo que ocasionaba discusiones y pleitos entre las autoridades distritales y el Tribunal Superior de Justicia, que era el encargado de decidir si eran o no legales los presupuestos de rentas y gastos de los distritos. Así, a lo que se asiste en el Estado Soberano de Bolívar es a un verdadero "laboratorio" fiscal en los distritos. Impuestos al pescado salado, ahumado, fresco o frito; a los establecimientos de trapiches para moler caña de azúcar; a los juegos permitidos por la ley en las temporadas de fiestas públicas como roletas, naipes, riñas de gallos; a los bailes; por la pesca del Sábalo decretado en el distrito de Bocachica en la provincia de Cartagena en 1878; a la leña que se cortara por los no vecinos para los buques de vapor en los terrenos del distrito de Pinillos; por el uso del peso de los distritos. Se llegó al extremo de incluir en los presupuestos de rentas las multas que se impusieran a las autoridades distritales y el de cancelar 20 centavos de carcelaje a los presos por el uso de la cárcel distrital como lo estableció el concejo distrital de Morroa en $1878^{26}$. Estos eran algunos de los impuestos decretados por los Concejos municipales en su afán de encontrar soluciones para mejorar la situación de las rentas distritales y cumplir con las normas constitucionales que les establecían obligaciones, pero sobre todo llevar a la práctica la premisa liberal que señalaba

\footnotetext{
${ }^{25}$ BBC, Diario de Bolivar, Cartagena, Julio 28 de 1877.

${ }^{26}$ BBC, Diario de Bolivar, Cartagena, agosto 14 de 1876; Gaceta de Bolívar, Cartagena, agosto 7 de 1870 y agosto 27 de 1868.
} 
que los distritos eran la razón de ser del sistema federal. En esa búsqueda de encontrar soluciones y alternativas el Concejo municipal de Arjona decretó en 1867 el siguiente presupuesto de rentas:

El Concejo municipal del distrito.... DECRETA:

Art.1. Desde el 1 de Febrero de 1867 quedan gravados en el distrito los ramos y operaciones siguientes:

1. Venta en pie de los ganados vacunos y de cerda.

2. Venta por menor de aguardientes.

3. Venta por menor de pescado salado, ahumado, fresco o frito.

4. Establecimientos de trapiches para moler caña de azúcar.

5. Los juegos permitidos por la ley en las temporadas de fiestas públicas.

Art. 2. El impuesto con que se gravan los ramos y operaciones mencionadas, es el que pasa a expresarse:

1. Por cada res que se venda en pie treinta centavos.

2. Por cada Cerdo, sea macho o hembra, que se venda también en píe, diez centavos.

3. Por cada venta menor de aguardientes un peso al mes.

4. Por cada carga de pescado salado o frito que se venda un peso.

5. Por cada carga de fresco o ahumado, cincuenta centavos.

6. Por cada trapiche establecido para moler caña, cincuenta centavos.

7. Por cada juego de roleta, un peso por cada noche que funcione ${ }^{27}$.

Pese a todos estos esfuerzos, la realidad era que ninguno de estos impuestos representaban unas entradas significativas para las arcas distritales y mucho menos se les podía aumentar su gravamen por la pobreza de los habitantes que vivían de la agricultura y la pesca. Gracias a los problemas fiscales que presentaban las entidades distritales, la mayoría no cumplía con la obligación de contribuir con los gastos establecidos por el Estado, por lo que les embargaba sus rentas.

\section{Guerra, contrabando y fabricación clandestina de aguardientes: vicisitudes para las rentas estatales}

Además de la pobreza, existían otros factores que contribuyeron para que el presupuesto de gastos fuera mayor que el de las rentas. Ningún elemento hacía tanto mal a las rentas estatales como la guerra y los levantamientos armados, que eran una constante en el periodo de estudio. Para Erasmo Rieux, presidente de la Asamblea Legislativa del Estado en 1873, desde que empezaban los conatos de revolución era preciso aumentar la fuerza pública, y como había que pagarle diariamente y de preferencia, desde ese momento no se podía hacer los demás gastos corrientemente y aun se dejaban de pagar en absoluto según

${ }^{27}$ AHC, Manuscritos, Fondo Gobernación, Sección Distritos y Municipios. Caja No 22, Arjona, enero 31 de 1867. 
la gravedad de las circunstancias. Igualmente el problema también era que en el Estado existía, según Rieux, "un núcleo de hombres, llámese partido, fracción, círculo o con cualquier otra denominación, con la ingrata tarea de conspirar momento por momento, sin tregua ni descanso, para derribar todos los gobiernos que existían" y esa amenaza permanente obligaba al gobierno a sostener una fuerza superior a los recursos del Estado y a dedicarle todo su tiempo exclusivamente a la vigilancia incesante de esos movimientos para desbaratarlos o contenerlos en su principio y conservar así la paz precaria en que vivían, quedando desatendidos y en abandono todos los demás negocios gubernativos y sin poder dedicarle ninguna mejora "por tener que vivir en permanente campaña, con el fusil al hombro y dando la voz de ¡QUIEN VIVE! a todas horas"28.

De igual forma, el fuerte contrabando que se hacía en todo el Estado de carne, harina, tabaco, café, azúcar y la fabricación clandestina de aguardientes eran otros problemas que entorpecían el presupuesto de rentas. Las autoridades distritales y provinciales argüían que la introducción ilícita de estos productos se debía al altísimo gravamen que tenían. Por ejemplo, lo normal era que el precio de una res fuera de $\$ 20$ o $\$ 16$ y se tenía que pagar por el impuesto al degüello la suma de $\$ 3,20$. Es decir, se cancelaba alrededor del $15 \%$ más del valor de la res. En 1873, Eugenio Baena manifestaba que uno de los impuestos de difícil percepción y que podía asegurarse que era defraudado de la manera más escandalosa, era el que gravaba el consumo de harina, tabaco, café, cacao y azúcar. La solución para Baena era rebajar la rata a su menor expresión con lo que el tesoro alcanzaría más provecho y se moralizaría la recaudación porque el contribuyente no tendría ya estimulo para procurar el fraude. Durante ese año, estaba gravado el consumo de dichos artículos en la forma siguiente: El kilogramo de harina con seis centavos; el de tabaco con dos y medio centavos; el de cacao, café y azúcar, con un centavo. Baena creía firmemente que produciría más el impuesto rebajando el consumo del kilogramo de harina a tres centavos; el de tabaco a un centavo, y el de cacao, café y azúcar, a medio centavo. Siendo tan moderado el impuesto, desaparecería el deseo de hacer el fraude, y de ahí vendría que se adquiriría el hábito de pagarlo y el aumento seguro de su producto ${ }^{29}$.

Ahora bien, no eran solamente los pobres los que practicaban el contrabando y la fabricación clandestina de aguardientes. En mayor medida, los sectores acomodados de la sociedad y hasta las autoridades distritales y provinciales tenían una altísima participación en estas actividades ilícitas. En 1871, el gobernador de Lorica ponía de presente que:

Lo que produce el aguardiente, ya por destilación, rectificación, introducción $\mathrm{y}$ venta por menor de aguardientes, poco o nada rinde a pesar de ejercer esa industria personas capitalistas, que abusando de su posición destilan y rectifican públicamente sin concertarse, y cuando se ven vigilados por la

\footnotetext{
${ }^{28}$ BBC, Gaceta de Bolivar, Cartagena, octubre 26 de 1873.

${ }^{29}$ BBC, Gaceta de Bolivar, Cartagena, octubre 14 de 1873.
} 
autoridad es que se patentan por un trimestre a lo más, un escándalo es que lo hagan por un año, como acaba de suceder en el distrito de Ciénaga de Oro con el Sr. Manuel Pretelt. Con estos antecedentes, creo conveniente poner en remate el producto de ese impuesto, pues la experiencia aconseja que es como puede obtener rendimientos el gobierno, pues la generalidad de los empleados son tolerantes en los fraudes, unas veces por las ataduras con quienes entran en las operaciones, y otras por no cargar con animosidades, y por último por el provecho directo que les deja semejante conducta... ${ }^{30}$

La dispersión de la población, la falta de vías de comunicación adecuadas y las grandes distancias a que estaban ubicadas algunas veredas de los distritos, hacían difícil, por no decir imposible, que se tuviera un control sobre las personas dedicadas a la producción de aguardientes. En comunicación enviada por el administrador de hacienda al gobernador de Mompos afirmaba que Pedro Argumedo, desde el 31 de marzo de ese año que dejó de destilar hasta el 20 de ese mes, aun no había depositado el cabezote de su aparato destilatorio en la colecturía de hacienda del distrito de Talaigua; pero como Argumedo tenía radicado su establecimiento en aquel distrito frente a la ciudad de Magangué, distante más de 10 leguas, por esa circunstancia desde 1869, fecha en que estableció la fábrica, había dejado de cumplir con la formalidad legal de depositar en la colecturía de Talaigua el cabezote en referencia. Pese a estas razones, el gobernador le ordenó terminantemente a Argumedo en cumplimiento de la ley "el depósito del cabezote de su aparato destilatorio en la colecturía de Talaigua, no obstante los inconvenientes que ofrece la distancia" 31 .

La falta de mataderos públicos también contribuía para que se cometieran fraudes ya que no se podía llevar un control sobre el número de reses y cerdos sacrificados. En 1858, el presidente del Estado, Juan Antonio Calvo, señalaba a la Asamblea Legislativa:

No es necesario hacer esfuerzo de ninguna especie para persuadirse del escandaloso fraude que se ha hecho. Tomando por punto de partida el producto del derecho establecido sobre la matanza de ganados, que ha existido en el Estado desde tiempo inmemorial en la misma cuantía en que hoy se haya establecido, poco más o menos y cuyos rendimientos casi han bastado para los gastos de las corporaciones municipales, a cuyos fondos ingresaban, vemos que dicho producto en los seis primeros meses del año, apenas han alcanzado a $\$ 12.542$, 65; el cual distribuido en los 181 días que trajeron esos seis meses, da un producto diario de $\$ 69,29$, correspondientes únicamente a 46,19 reses dadas al consumo cada día en todos los 81 distritos que componen el Estado; y que calculando ese número de reses por su peso en carnes en 5.542,80 Kilogramos, o sean 5542,800 gramos, apenas tocaría a cada habitante para su alimentación 30,28 gramos jesto es menos de una

\footnotetext{
${ }^{30} \mathrm{BBC}$, Diario de Bolivar, Cartagena, agosto 26 de 1871.

${ }^{31}$ AHC, Manuscritos. Fondo Gobernación, Sección Distritos, Mompox, mayo 2 de 1878, No 193.
} 
onza!, quedando privados de tomar carne de cerdo y del uso de la manteca de éste, pues la exigüidad del producto del derecho de que vengo hablando no ha permitido que entre la combinación del cálculo hecho, lo que se haya cobrado por el impuesto que grava el ganado de cerda, que viene a ser igual respecto de tres cabezas al que grava una de ganado vacuno ${ }^{32}$.

De igual forma, la ley que gravaba los efectos extranjeros no producía los resultados que se esperaban. En 1861 el gobernador de la provincia de Barranquilla argumentaba que la causa fundamental de este bajo rendimiento era "el contrabando escandaloso que se comete por los pueblos de la banda oriental del río Magdalena”. Doce años después, el gobernador de la provincia de El Carmen, anotaba la misma situación: "Sr. secretario general de Estado...respecto a la harina y el café, es cierto que el infrascrito nada ha recaudado por el impuesto con que están gravados, pero esto consiste en que las introducciones, por lo regular, se hacen en los días de ferias y casi siempre a deshoras de la noche y no puedo evitar mis precauciones para evitar el fraude" ${ }^{33}$. La introducción ilícita de harina a la provincia de El Carmen se hacía a través de los puertos de Tenerife y Plato en el Estado del Magdalena y luego eran transportados a Zambrano, Jesús del Río y las Mercedes, como lo contaba en 1862 el gobernador de la provincia de Barranquilla

\begin{abstract}
Varias veces se han remitido a Tenerife, Plato y otros puntos inmediatos a los puertos de "Las Mercedes" y "la gobernación Zambrano" grandes cantidades de harina extranjera. Es verdad que se llevan con las respectivas guías y que, con las tornaguías se comprueban las introducciones en los primeros citados pueblos.

Pero presumo que ellos se transportan a los segundos, con el objeto de hacer conducir la harina a la populosa y laboriosa Villa de El Carmen, y que esa operación se verifica tal vez sin que llenen los requisitos legales. Al pensar así, soy inducido por las reflexiones que naturalmente me hago de que Tenerife, Plato y otros distritos de la banda oriental del Magdalena, no tienen los recursos ni la población bastante para consumir las porciones de dichos artículos, que en grande escala se hacen aparecer como introducidos en ellos. Al verificarse la extracción de esta Ciudad, el Sr. Administrador de hacienda, cuida de señalar los barriles con esta marca E. B., y esta precaución no basta para impedir los fraudes ${ }^{34}$.
\end{abstract}

\footnotetext{
${ }^{32}$ BBC, Gaceta de Bolivar, Cartagena, octubre 1 de 1858.

${ }^{33}$ Sobre los informes de los Gobernadores de las provincias de Barranquilla y El Carmen ver: BBC, Gaceta de Bolivar, Cartagena, octubre 14 de 1861 y julio 18 de 1873.

${ }^{34}$ Ver: AHC, Manuscritos. Fondo Gobernación, Sección Provincias, Barranquilla, junio 8 de 1862 y BBC, Gaceta de Bolivar, Cartagena, julio 23 de 1874.
} 


\section{"Entre nosotros, se considera más vivo el que burla mejor las leyes fiscales"}

Ni siquiera el impuesto sobre la renta, caracterizado por los liberales como el más equitativo y fácil de recaudar, dio los rendimientos que se esperaban. Los motivos eran por los abusos de las juntas distritales y provinciales; la falta de un censo y de un catastro general que permitiera de manera sensata conocer las rentas de que disponían los ciudadanos del Estado; la dispersión de la población que se hallaban en sitios y parajes alejados de las cabeceras distritales; por el enfrentamiento entre liberales y conservadores, etc.

Al igual que los Estados Soberanos de Cundinamarca, Boyacá, Santander, Panamá y Tolima ${ }^{35}$, el de Bolívar introdujo en 1869 el impuesto progresivo de la contribución directa. El impuesto sobre la renta era una contribución anual que gravaba todas las industrias, profesiones y empleos de los habitantes del Estado, nacionales o extranjeros, que no estuvieran exceptuados por leyes especiales, que produjeran una renta anual de 120 pesos y a los que sin residir en el Estado, tuvieran en él la renta expresada (inicialmente fue de 300 luego de 240 y finalmente se llegó a los 120). No estaban sujetos a este gravamen, las rentas procedentes de fincas urbanas ni las que devengaban los empleados públicos del Estado por sus sueldos. La Asamblea Legislativa distribuía la cantidad fijada en la ley de presupuestos, como impuesto sobre la renta entre las provincias del Estado, atendiendo a su riqueza y población. De igual forma, el poder Ejecutivo distribuía entre los distritos de cada provincia la suma que había asignado la Asamblea legislativa, atendiendo a su riqueza y población. La suma menor que podía señalar el poder Ejecutivo era de $\$ 120$ anuales ${ }^{36}$.

Con esta medida, el Estado, financieramente, dependía del contingente enviado por las provincias; dándose, por tanto, el establecimiento de una contribución directa del tipo "cupo provincial" que no gravaba a los individuos sino a las entidades provinciales ${ }^{37}$. Es decir, a cada provincia el Estado le asignaba una cantidad por concepto de impuesto sobre la renta y luego estas distribuían y dividían entre los ciudadanos aptos de cada distrito la cantidad que a cada una le correspondía. Verbigracia, en Diciembre de 1874 la Asamblea legislativa del Estado aprobó para el año de 1875 la suma de $\$ 80.000$ por concepto de impuesto sobre la renta y se distribuyó entre las provincias de la siguiente manera: a la de Barranquilla le correspondió la suma de \$18.750,oo; El Carmen: \$5.937,50,oo; Cartagena: \$15.000,oo; Corozal: \$5.625,oo; Chinú: \$7.500,oo; Lorica: \$7.500,oo; Magangué: \$3.750,oo; Mompox: \$5.937,50; Sabanalarga: \$4.375,30; Sincelejo: \$5.625,oo. Seguidamente, las autoridades provinciales dividían la suma que le había sido asignada a las provincias, entre cada uno de los distritos que las conformaban. Para establecer la

${ }^{35}$ Malcolm Deas, "Los problemas fiscales en Colombia durante el Siglo XIX", en Del poder y la gramática, Bogotá, Tercer Mundo, 1993.

${ }^{36}$ BBC, Gaceta de Bolivar, Cartagena, enero 20 de 1873.

${ }^{37}$ E. Donjuán, "Las finanzas públicas en Sonora en la primera mitad del siglo XIX. La cuestión fiscal", p. 4. 
cantidad se tenía en cuenta el número de sus habitantes y la riqueza de los mismos. Por ejemplo, la de Barranquilla dividió ese año la suma que le había sido asignada de esta forma: al distrito capital le fue adjudicado la cantidad de $\$ 16.725$,oo; Malambo: $\$ 150$,oo; Palmar de Varela: \$150,oo; Sabanagrande: \$250,oo; Santo Tomás: \$375,oo; Soledad: \$575,oo; Tubará: \$375,oo; Galapa: $\$ 150, \mathrm{oo}^{38}$.

No obstante, este procedimiento tenía problemas porque sucedía que algunos distritos repartían la cantidad que se les asignaba entre un sinnúmero de contribuyentes que no estaban en aptitud de ser calificados, porque su mira era llenar la cifra total de la asignación y al verificarse el cobro por el empleado de hacienda respectivo, era que venía a percatarse el capcioso procedimiento, que era ya irremediable. Ni siquiera la repartición que le correspondía a las provincias se escapaba de los sesgos personales, políticos e ideológicos. En 1864, el gobernador de Chinú sugería que la contribución sobre la renta debía establecerse de modo que el gravamen impuesto a las provincias no quedara sujeto a la mayor y buena fe de los encargados de hacer las calificaciones, pues se había dado el pernicioso ejemplo de que por favorecer intereses particulares, aparecían provincias de iguales recursos, con rentas completamente distintas y cuyo mal no había podido corregirse por no estar previsto en la ley “...porque entre nosotros, se considera más vivo el que burla mejor las leyes fiscales"39.

Pero ¿de qué manera se llevaba a cabo el cobro de este impuesto? En cada distrito se reunía una junta denominada "junta calificadora del impuesto sobre la renta" compuesta por el alcalde, el presidente del concejo, el procurador municipal y dos vecinos sorteados entre los contribuyentes del distrito. La junta era presidida por el alcalde y tenía por secretario al de la alcaldía, con voz pero sin voto. En los distritos capitales, las juntas calificadoras estaban compuestas del gobernador, del fiscal de la provincia, del presidente del concejo, del administrador de hacienda y tres ciudadanos vecinos. Estas juntas podían repartir entre los contribuyentes hasta un $25 \%$ más de la suma que se les había señalado y les correspondía exclusivamente a los distritos, pero no se les entregaba mientras no se hubiese enterado lo que le correspondía al Estado por cuota mensual. El 25\% se debía emplear obligatoriamente en los gastos de local y mobiliario de la instrucción pública ${ }^{40}$.

Sin embargo, los habitantes estaban a la merced de las decisiones, muchas veces arbitrarias, de los miembros de las juntas calificadoras. Naturalmente, que en medio de una sociedad de carácter rural e iletrada, en su gran mayoría, los que integraban las juntas pertenecían a los sectores "privilegiados" y que tenían la facultad de saber leer y escribir y como cosa rara ellos haciendo uso de ese poder lo que hacían era disminuir sus ingresos y los de sus parientes y allegados, haciendo recaer el peso del impuesto sobre los sectores

\footnotetext{
${ }^{38}$ BBC, Gaceta de Bolivar, Cartagena, diciembre 31 de 1874.

${ }^{39}$ BBC, Gaceta de Bolivvar, Cartagena, agosto 29 de 1869.

${ }^{40} \mathrm{BBC}$, Gaceta de Bolivar, Cartagena, enero 20 de 1873.
} 
menos favorecidos. De la situación anotada dejaron constancia los vecinos de Arroyo Grande, en la provincia de Cartagena, quienes elevaron un memorial al presidente del Estado quejándose de la forma en que la junta calificadora hizo la repartición del impuesto sobre la renta. En apartes del memorial señalaban:

El día 18 del que espira se reunió en la cabecera de este distrito, una junta a la que se le dio el nombre de calificadora del impuesto sobre la renta, cuyos miembros fueron los señores Norberto Medina, Presidente del Concejo; Lino Medina, hermano del expresado; Marcelino Torrente, Preceptor de la escuela y cuñados de los susodichos; presidida dicha junta por el Sr. Julián Guzmán como Alcalde suplente que no tiene los conocimientos para desempeñar tan delicadas funciones, cuya junta procedió a hacer el reparto del impuesto salvando los intereses de su familia y los de ellos mismos, que son los más ricos de este distrito, como es público y notorio y gravando a personas, que si bien es cierto que no se están muriendo de hambre, también es cierto que sus rentas consisten en el hacha, el machete, las atarrayas de los pescadores y el trabajo material de los 365 días que tiene el año, pues dos vacas y un burro que posee cada individuo de los gravados, no es una renta que pueda producir de utilidad ciento veinte pesos al año, que es el mínimo de la rata en que está calculado el impuesto sobre la renta ${ }^{41}$.

De igual forma se refería el gobernador de la provincia de Barranquilla en 1876, manifestándole al secretario general del Estado para que se formara una idea de cómo se administraba la cosa pública en el distrito de Tubará:

El Sr. Presidente del Concejo municipal, persona allí de las más entendidas y circunspectas, se prestó como miembro de la junta calificadora a inscribir en la lista de contribuyentes, con fuertes sumas, a personas notoriamente pobres unas, y en estado de mendicidad y desconocidas otras; mientras que colocó a los más pudientes y acomodadas de aquel distrito en cuotas insignificantes. Es así como en aquel distrito, se sirve, de ordinario, a los intereses del gobierno ${ }^{42}$.

Para corregir los abusos que cometían las juntas distritales y provinciales fue organizada en 1873 una nueva junta denominada "Superior Calificadora de la renta", que residía en la capital del Estado y estaba conformada por el secretario general, en representación del Presidente, el contador general, el tesorero general y dos ciudadanos vecinos de la capital, nombrados por la Asamblea Legislativa. Llamada esta junta a corregir los errores de las provinciales, en muy pocos casos llenaba su misión. Casi siempre desacertaba. Las distancias enormes a que se encontraban las agregaciones y caseríos de los distritos, la

${ }^{41}$ BBC, Diario de Bolivar, Cartagena, enero 4 de 1876.

${ }^{42}$ BBC, Diario de Bolivar, Cartagena, agosto 11 de 1876. 
carencia de los datos necesarios para cumplir con la ley y la inexactitud de los que recibía, eran las causas que hicieron nugatorios los fines que el legislador se propuso con la creación de la Junta Superior. La impopularidad de este impuesto y la tendencia general que se advertía a resistir su pago y la falta de los conocimientos necesarios para la regulación del impuesto llevó a que el Estado tomara la decisión de suprimirlo en 1878 bajo la presidencia de Rafael Núñez y se estableció el del cobro del 15\% sobre el consumo de mercancías extranjeras.

\section{La resistencia consuetudinaria al pago de las contribuciones}

Otro factor que entorpecía la marcha de las rentas estatales, se debía a la resistencia consuetudinaria de los ciudadanos al pago de las contribuciones. Diferentes factores intervenían para que los habitantes asumieran esta actitud. Una de ellas era que los ciudadanos afiliados al partido conservador no cancelaban los impuestos porque de esa manera se entorpecía la marcha de la administración pública estatal, a la que consideraban ilegítima. Para los conservadores, primero era el sentido de pertenencia hacia la colectividad política en la que militaban, y por la que daban la vida, que la institución del Estado. A muchos conservadores no se les había olvidado, y mucho menos perdonado, que fueron despojados en 1859 del poder político en el Estado por medio de la coacción y la vía armada a manos del partido liberal liderado por Juan José Nieto ${ }^{43}$.

Distritos conservadores que se caracterizaron por no pagar las contribuciones fueron Corozal, Pinillos, Simití, Ayapel y Pasacaballos. En el mes de mayo de 1865, el alcalde de Corozal le comunicaba al gobernador de la provincia que le remitía "la cantidad setenta y cuatro pesos recaudados de la contribución del Estado, teniendo la pena de comunicarle que en esta población no se puede dar puntual cumplimiento a las órdenes superiores, porque hay que conciliar en todo con cierta política local a consecuencia de la falta de apoyo moral que aquí tienen las autoridades”44. En Ayapel la situación era mucho más drástica. Allí era imposible hacer la recaudación de las contribuciones que se adeudaban en el distrito sin el auxilio de la fuerza pública, debido al poco o ningún respeto que tenían sus habitantes a las leyes y autoridades. En 1877, el gobernador refiriéndose a este distrito argumentaba que allí no se vivía bajo el amparo de la ley, sino bajo el régimen del terror que inspiraban ciertos individuos; no había quien pagara las contribuciones públicas sino obligadas por la fuerza de las bayonetas; no había administración de justicia porque cada cual se la daba a su modo, y era tal la inseguridad, tal el menosprecio y los peligros a que estaba expuesta la misma autoridad, que no había quien quisiera ni quien pudiera desempeñar la alcaldía de aquel distrito:

\footnotetext{
${ }^{43} \mathrm{Al}$ respecto ver Orlando Fals Borda, El Presidente Nieto, Bogotá, Carlos Valencia eds., 1984.

${ }^{44}$ BBC, Gaceta Oficial del Estado Soberano de Bolívar, Cartagena, mayo 12 de 1865; Gaceta de Bolívar, julio 23 de 1874, y Diario de Bolívar, Cartagena, julio 22 de 1878.
} 
En Ayapel se lleva la hostilidad al gobierno hasta tal punto, que basta que un ciudadano llegue allí con el carácter de empleado público para que todas las puertas se le cierren; es tan difícil llevar a cabo las órdenes que provienen de cualquiera de los poderes públicos, que prefieren los sinsabores de un juicio de responsabilidad antes que cumplirlas. No hace muchos días que el $\mathrm{Sr}$. Alcalde del distrito de que me ocupo, devolvió cerrado al Sr. Juez de la provincia un despacho en que se le comisionaba para llevar a efecto la restitución de unos terrenos, manifestando en su nota que no se atrevía a verificar aquel acto de justicia.

En Ayapel la autoridad es la befa, el escarnio de todos, sucediendo algunas veces que no solo se les haya irrespetado, sino hasta abofeteado y hecho ocultar... ${ }^{45}$

Pero más allá de la afiliación política, el problema estaba en la incapacidad del Estado para extraerles impuestos a las clases propietarias. Lo mismo que hacían los conservadores lo practicaban los liberales. En 1868, el gobernador de Barranquilla haciendo un análisis del cobro de la contribución comercial en la provincia bajo su mando señalaba:

El impuesto a la industria comercial tal como existe, es una burla... pero como entre nosotros el comerciante extranjero no quiere pagar impuesto, porque a él poco le importa el país y su gran interés es ganar el dinero para abandonarlo pronto, y el comerciante conservador no quiere tampoco pagar impuestos porque a él poco le importa, pues entiende que los liberales gobiernistas son todos una partida de pícaros ladrones, y los comerciantes liberales tampoco quieran pagar impuestos porque ellos son amigos del gobierno, claro está que ni así tampoco nadie declararía su renta ni después de hecho balance, ni sabiendo cuanto es el tanto por ciento del impuesto ${ }^{46}$.

Para terminar de completar el cuadro de vicisitudes que enfrentaba las rentas estatales, las pocas que se recaudaban muchas veces eran robadas por los colectores distritales y los alcaldes. Verbigracia, en 1878 Pedro Blanco García, comisionado fiscal, señalaba que el 13 de Octubre se dirigió a Chimá, Provincia de Lorica, y luego de verificar las operaciones fiscales respectivas, visitó Momil y Purísima. En el primero dedujo dos alcances líquidos, contra los dos excolectores por las sumas de $\$ 135,83$ y $\$ 305,05$. Sin embargo, no pudo hacer nada porque ambos estaban prófugos. Lo que sorprendía al comisionado era "contemplar que en distritos de segundo orden, donde los impuestos no alcanzan ni a doscientos pesos anuales, y que están en contacto diario con las capitales de la provincia, se hayan podido cometer desfalcos de tanta significación”, lo que demostraba, de una manera incontrovertible, la inercia o incompetencia de las autoridades superiores del ramo de la hacienda, en la época en que esos desfalcos se consumaron ${ }^{47}$.

\footnotetext{
${ }^{45} \mathrm{BBC}$, Diario de Bolivar, Cartagena, julio 31 de 1877.

${ }^{46}$ BBC, Gaceta de Bolivvar, Cartagena, agosto 27 de 1868.

${ }^{47}$ BBC, Diario de Bolívar, Cartagena, noviembre 29 de 1878.
} 


\section{EI sistema de arrendamiento y la consolidación de monopolios económicos en el Estado}

Ante la imposibilidad de establecer un monopolio fiscal en el Estado, la medida más importante adoptada por la Asamblea Legislativa fue someter al sistema de arrendamiento los principales gravámenes del sistema tributario como el consumo de carnes de ganado vacuno y de cerda, de harina, tabaco, café, cacao y azúcar, la destilación y rectificación de aguardientes, y el cobro del $15 \%$ sobre el consumo de las mercaderías extranjeras. De esta manera, el cobro de estos impuestos recayó sobre ciudadanos particulares, los que establecían un contrato con el Estado o los distritos. El acto del remate tenía lugar en las capitales de provincia, ante una junta compuesta por el gobernador que la presidía, del administrador de hacienda y el fiscal respectivo, teniendo como secretario el de la gobernación.

Lo paradójico fue que con el arrendamiento de los impuestos se logró lo que el Estado nunca pudo hacer: la consolidación de verdaderos monopolios económicos, porque los arrendamientos quedaban en las manos de las familias que ostentaban el poder político y económico en cada una de las provincias que integraban el Estado, convirtiéndose para aquellas en uno de los negocios más rentables. Para Marco Palacios y Elber Berdugo Cotera el sistema de arrendamiento en los Estados, y luego en los departamentos, lo que creo fueron extendidas redes de clientelismo político. Las razones por las que estas pasaron a ser controladas por verdaderas "roscas" políticas estaban asociadas al pago de favores políticos; a la contraprestación económica que recibían al aprobar los contratos; a las continuas necesidades de dinero que tenían los gobiernos para sufragar los ingentes gastos en que incurrían por diferentes conceptos y que no podían atender, no quedándole otra alternativa que acudir a financistas particulares para solucionar los faltantes; al interés de favorecer a amigos, allegados, etc. ${ }^{48}$. Verbigracia, en 1873 Manuel Manotas, gobernador de la provincia de Sabanalarga, le concedió el contrato del arriendo del consumo de carnes de ganado vacuno y de cerda de toda la provincia a su hermano, Narcés Manotas, por la suma de 7.666,43. Tres años más tarde, José Vicente LLinás, le entregó el mismo contrato a su colega político Pedro A. Polo y su fiador fue Nicolás Manotas, emparentado por lazos familiares con el gobernador. En el caso del distrito de El Carmen durante los años 1875 y 1876, el arrendamiento estaba en manos de Manuel Cabeza y el fiador era Valentín Pareja, los hombres más influyentes en la provincia en mención. En 1876, el gobernador de la provincia de El Carmen era Bartolomé Marichal, quien hacía parte del círculo político de Cabeza. De hecho, un año después sería nombrado por éste secretario de gobierno en la sexta administración de Manuel Cabeza como gobernador de El Carmen ${ }^{49}$.

\footnotetext{
${ }^{48}$ Marco Palacios, Entre la legitimidad y la violencia. Colombia, 1875-1994, Bogotá, ed. Norma, 199, p. 38, y Elber Berdugo, "José María Sierra: las rentas públicas estatales y la concentración patrimonial de la riqueza en Colombia, 1877-1909”, en Memorias del XIII ${ }^{\circ}$ Congreso Colombiano de Historia. Cd. digitalizado.

${ }^{49}$ BBC, Diario de Bolivar, Cartagena, marzo 10 de 1876.
} 
Además de los Manotas, Polo, Cabeza y Pareja, otras de las familias que controlaban el poder político en las provincias y que "ganaron" el arriendo del impuesto en mención fueron los Hermanos Rieux en los distritos de Sabanagrande, Palmar de Varela y Santo Tomás en la provincia de Barranquilla; Ventura García en Magangué; Francisco González Carazo en el distrito de Santa Ana, provincia de Cartagena y Andrés Santodomingo Vila en San Andrés y San Benito Abad en la provincia de Lorica ${ }^{50}$. Estos dos últimos eran parientes de Antonio González Carazo y Ramón Santodomingo Vila, los hombres con más poder político en el Estado de 1864 a 1875, cuando fueron desplazados por Núñez.

En las provincias en las que sus elites se encontraban divididas, el arrendamiento de los impuestos generaba enfrentamientos y demandas judiciales, como sucedió en Chinú en 1870 cuando se enfrentó Manuel Mercado y Rafael D. Pineda. El primero fue diputado de la provincia en 1873, 1875 y 1881. Además, ganó el arriendo del cobro del consumo de carnes en el distrito de Ayapel en 1879. El segundo era miembro de la familia con más poder político y económico en esa provincia ${ }^{51}$. En el año en mención, Mercado elevó un memorial al Secretario general del Estado quejándose de la forma en que se llevó a cabo el remate del arrendamiento del cobro del consumo de carnes de ganado vacuno y de cerda en la provincia de Chinú. Según Mercado "organizaron varios individuos en esa capital una compañía de la comparsa del gobernador, figurando entre ellos un hermano de éste, para rematar los derechos de consumo de carnes de algunos distritos y especular en los actos de remate de la provincia. Para mayor seguridad y eficacia del plan, todos los fiadores hábiles calificados por el gobierno debían salir de la misma compañía, con rarísimas excepciones. Todo competidor era rechazado por el gobernador con estas palabras: "El fiador de Ud., no está en la lista de los fiadores hábiles; la firma de su fiador no está en papel sellado, y por lo mismo no se admite a Ud., ninguna postura".

El acto del remate avanzaba y "la base del de esa capital permanecía quieta, apenas cubierta por la compañía", hasta que dos de los competidores rechazados, señores Pedro M. Solana y David Mercado, hermano de Manuel, presentaron en papel sellado la firma de un sujeto que habían inscrito en la lista de fiadores, creyendo sin duda que no se prestaría a la fianza. Fue entonces que continuaron las pujas desde la base hasta doscientos dos pesos con cuarenta centavos, más el $10 \%$ adicional en que se le adjudicó el remate a la compañía en la persona del socio Samuel Angulo. El hecho de haber pedido certificación de la suma en que fue adjudicado el remate, daba una idea de cuanta inseguridad ofrecía aquel acto por parte del gobernador. Por ejemplo, varias de las personas admitidas como fiadores, no tenían en bienes raíces la responsabilidad requerida por las disposiciones ejecutivas sobre la materia, como le sería fácil demostrarlo si su interés en el asunto, pasará más allá del

\footnotetext{
${ }^{50} \mathrm{BBC}$, Diario de Bolívar, Cartagena, marzo 10 de 1876.

${ }^{51} \mathrm{Al}$ respecto ver: R. Flórez, El uso privado de la autoridad pública en el Estado Soberano de Bolívar, 1863-1878.
} 
simple propósito de informarlo sobre lo sucedido para efectos administrativos y que pusieran algún remedio para lo venidero. Para Mercado:

No es este un denuncio que debéis pasar a la autoridad judicial para la correspondiente averiguación; no señor: Me ocupo del derecho de petición y solo pido o indico respetuosamente lo siguiente: Que dispongáis sean reformadas y en efecto se reformen las disposiciones Ejecutivas sobre fianzas en remates y contratos en que tenga interés el Estado, así como para asegurar el manejo de los empleados de hacienda, en el sentido de que la aceptación del fiador y el bastante o de la fianza, sea atribución de una junta cuyos miembros sean nombrados por le Poder Ejecutivo y de la cual haga parte el Gobernador.

Todo cuanto tienda a sacar estos asuntos del conocimiento y decisión de los empleados ordinarios de cargo lucrativo, sería conveniente a las rentas y seguridad del Estado ${ }^{52}$.

En la práctica, los arrendamientos eran ficticios puesto que los postores ya habían acordado de antemano su reparto. En noviembre de 1878, Jorge A. Abella elevó un memorial al Secretario general en el que solicitaba el enjuiciamiento del gobernador de la provincia de Barranquilla por contravenir las leyes que disponían el arrendamiento del impuesto al consumo de mercancías extranjeras que se causara en 1879. Además de las razones que expuso en apoyo de la solicitud, se vio en el caso de remitir al Secretario una documentación con los testimonios de Jacinto Consuegra y Teodosio Moreno, administrador de hacienda y fiscal de la provincia respectivamente y por la que vería comprobada sus aserciones. Además:

Por las declaraciones a que he aludido al Sr. Secretario vendrá en conocimiento de que a pesar de haber hecho una postura ventajosa al fisco, este no fue admitido a pesar de haber sido hecho en tiempo hábil o de que ilegalmente se admitió la proposición del Sr. Francisco J. Palacio, quien era el gobernador de la provincia hasta el mes de Marzo de este año.

Por las razones que entonces alegué y por las expuestas y en vista de las declaraciones que acompaño, creo que el Secretario procederá a declarar nulo todo lo hecho en esta Ciudad por no estar arreglado a la ley, y así lo espero de su elevado criterio y recto juicio ${ }^{53}$.

Por lo general, era a los ganaderos a quienes se les adjudicaba el arrendamiento del consumo de carnes de ganado vacuno y de cerda. O cuando el rematador no lo era, su fiador si y el negocio de este consistía en venderle el ganado que se iba a consumir en la provincia o en el distrito, como sucedió en la provincia de Sabanalarga en 1876 cuando el

${ }^{52}$ BBC, Diario de Bolívar, Cartagena, diciembre 9 de 1870.

${ }^{53}$ AHC, Manuscritos, Fondo Gobernación, Sección, Hacienda, Barranquilla, noviembre 9 de 1879. 
arriendo lo "ganó" el abogado Pedro A. Polo, quien no era ganadero, pero su fiador era Nicolás Manotas, reconocido ganadero de la provincia. Para éste último las ganancias eran cuantiosas. Los remates más apetecidos eran la de los distritos capitales porque contaban con un mayor número de habitantes y por sus vías de comunicación, etc. El pago podía hacerse de contado o por meses y debían demostrar ante el notario público del distrito que contaban con los suficientes recursos económicos representados en capital o en bienes raíces.

Sin embargo, el que se estableciera el sistema de remate no significó que desapareciera el contrabando. Ahora quienes lo practicaban eran los mismos rematadores como sucedía en la provincia de Barranquilla, específicamente en los distritos de Salgar y Sabanilla. Para el gobernador la única razón que podía haber para que se creyera que convenía cobrar en remate y no en administración el impuesto del consumo de carnes era la de mayor provecho para el tesoro; pero él creía que si bien podía ser cierto que a la administración de hacienda entraría el valor de seis u ocho reses más de las que aparecían beneficiadas en cada mes, también era posible que el impuesto que esas reses representaban, $\$ 216$,oo o $\$ 288$,oo anuales, podría determinar un perjuicio de mayor consideración al que creía que existía, perjuicio irremediable por lo menos en un año, una vez hecho el remate. Según el gobernador:

No he podido yo, averiguar si alguna carne salada que he oído decir llevan a Colón, es o no beneficiada clandestinamente, pero de lo que si no se puede dudar es que esos remate de los caseríos de Salgar y Sabanilla, hechos hasta con un $50 \%$ a la base que la ley permite fijar, no compensaría ni con mucho los perjuicios que pudiera sufrir el tesoro, si como es demasiado posible la persona que rematara el susodicho impuesto estableciera una salazón de carnes en grande escala para exportarla y aun para el consumo de esta localidad, puesto que ya, sin correr el riesgo de ser perseguida como defraudadora podría, dar remate a todo el ganado, que tuviera a bien. Esto es precisamente lo que se me ha informado que se pretende hacer por una o más hacendados de esta provincia ${ }^{54}$.

En definitiva, ninguna de las medidas implementadas por los gobiernos del Estado logró equilibrar los gastos con las rentas. Además, así no se hubiesen presentado guerras y revueltas internas, ni hubiese contrabando, ni evasión de impuestos, se podían nivelar estos. La verdadera razón del desequilibrio era la pobreza del Estado y de sus habitantes, como tuvieron que aceptarlo tristemente sus dirigentes. "Pero sin la alteración del orden público hubiera venido a dar el último golpe al tesoro del Estado, la situación de este sería siempre penosa, por que las rentas y contribuciones no han producido lo que calcularon

${ }^{54}$ AHC, Manuscritos. Fondo Gobernación, Sección Hacienda. Caja No 21. Barranquilla, octubre 24 de $1874, \mathrm{~N}^{\mathrm{o}} 372$. 
los legisladores de 1872, mientras que los gastos presupuestados son invariables", decía Erasmo Rieux en 1873.

Ante esta situación lo que cotidianamente se hacía por parte del Estado era recurrir a la emisión de bonos o de billetes con un precio menor del 15\%, a empréstitos a comerciantes, ganaderos, hacendados y en tiempos de guerra se establecían los de carácter forzoso, lo que aumentaba la deuda que mantenía la administración estatal con los ciudadanos particulares, los que aprovechaban para sacar el mayor provecho. A ellos eran a quienes el Estado les adjudicaba los contratos de construcción de obras públicas, de cárceles, de los remates de los impuestos, etc.

La falta de recursos económicos llevó a que a los empleados públicos se les pagaran bajos sueldos, que se les retrasara el pago de estos hasta por seis u ocho meses, lo que era la norma, o que estos tuvieran que venderlos. Ni siquiera Cartagena, capital del Estado, se escapaba de esta situación. En 1876, el presidente de ese mismo organismo, Francisco V. de la Espriella, informaba al secretario general, que los empleados que laboraban bajo su dependencia, por su condición de pobreza, "se ven forzados a vender sus sueldos con un cincuenta por ciento de descuento". En el mes de Febrero de ese año, el director de la escuela pública de varones del distrito de Rosavieja, provincia de Sabanalarga, Javier Cerezo, se vio en la necesidad de vender el sueldo que recibiría por ese cargo en los meses de Enero y Febrero a Pedro A. Polo y Víctor Manuel Consuegra. Cerezo señalaba:

Conste por el presente que cedo y traspaso a favor de los señores Víctor Manuel Consuegra y Pedro A. Polo los sueldos que me corresponden como director de la escuela pública de varones del distrito de Rosavieja correspondientes a los meses de Enero y el presente, como también los que devengare en los meses de Marzo a Junio... de este traspaso he recibido de dichos señores el valor íntegro de los sueldos mencionados. Con su consecuencia me obligó a responder a los referidos Señores Polo y Consuegra del reintegro de dichos sueldos en el caso de que dichos señores no puedan percibirlos por trastorno del orden público o por cualquier caso fortuito yo no pueda devengar los sueldos que les he vendido ${ }^{55}$.

En síntesis, la falta de recursos económicos tanto de las administraciones estatales, provinciales y locales provocó que el Estado cotidianamente tuviera que solicitar préstamos a comerciantes, hacendados y ganaderos, etc., lo que generó una dependencia de aquel hacia éstos, quienes sacaban el mayor provecho. Ya no era necesario comprar, de manera directa, los cargos públicos como en el periodo colonial. Además de ser estos sectores los encargados de ejercer los cargos públicos estatales, provinciales y distritales, eran prestamistas del Estado al que representaban.

${ }^{55}$ BBC, Diario de Bolívar, Cartagena, julio 15 de 1876 y AHC, Manuscritos, Fondo Gobernación, Sección Tesorería. Sabanalarga, febrero 27 de 1876. 
$\mathrm{Al}$ construir un Estado cuya misión principal era la de otorgar puestos y favores, el sector dirigente se aseguró de que solo ellos, detentaran el poder en los diversos niveles del aparato estatal. Lo que les ofrecía, por lo demás, el control político de sus diversos territorios y los convertía en la minoría que, en el conjunto del Estado, ejercía el verdadero poder. 